\title{
Experimental Study on the Ultimate Bearing Capacity of Long Basalt Fiber- Reinforced Concrete (BFRC)-Filled Steel Tube Columns under Axial Compression
}

\author{
Wang Xinzhong ${ }^{1,2, *}$, Li Chuanxi ${ }^{1}$ and Zhou Wei ${ }^{2}$ \\ ${ }^{I}$ School of Civil Engineering and Architecture, Changsha University of Science and Technology, Changsha, 410114, China \\ ${ }^{2}$ School of civil engineering, Hunan City University, Yiyang, 413000, China
}

Received 19 May 2016; Accepted 15 September 2016

\begin{abstract}
The strength and ductility of core concrete are important factors influencing the bearing capacity of concrete-filled steel tube (CFST) structures, and an appropriate mixing amount of basalt fiber can change the toughness index of concrete. To examine the reinforcing effect of basalt fiber on the bearing capacity of long CFST columns, axial compression bearing capacity experiments were conducted on 15 long basalt fiber-reinforced concrete (BFRC)-filled steel tube columns and 9 long CFST columns to determine the ultimate bearing capacity, load-displacement curve, and load-strain curve of the experimental columns. A comparative analysis was then performed on the experimental results and experimental characteristics of the bearing capacity to differentiate long fiber CFST columns from long CFST columns. Results revealed that compared with CFST columns, BFRC-filled steel tube columns displayed improved ultimate bearing capacities under experimental level. Specifically, for core concrete added with $12 \mathrm{~mm}$ basalt fiber, the ultimate bearing capacities of BFRC-filled steel tube columns with wall thicknesses of 4,5 , and $6 \mathrm{~mm}$ were improved by $9.7 \%, 8.6 \%$, and $7.3 \%$, respectively. For core concrete filled with $24 \mathrm{~mm}$ basalt fiber, the ultimate bearing capacities of long BFRC-filled steel tube columns with wall thicknesses of 4,5 , and $6 \mathrm{~mm}$ were improved by $7.8 \%, 5.7 \%$, and $3.1 \%$, respectively. Thus, basalt fiber improves the ductility of CFST columns. The findings of this paper is of important engineering indicate the promising application value of basalt fiber in long CFST columns.
\end{abstract}

Keywords: Long Concrete-Filled steel tube (CFST) columns, Basalt fiber, Axial compression, Ultimate bearing capacity

\section{Introduction}

Concrete-filled steel tubes (CFST) are composite materials formed by filling concrete into thin-wall steel tubes. Characterized by advantages such as excellent bearing capacity, rapid construction, and good anti-seismic performance, these structures have extensively utilized in bridge and architectural engineering. The load-bearing capability of CFST structures greatly depends on the performance of core concrete greatly influence on, and previous studies have demonstrated that the mechanical property of core CFST is the key factor determining the bearing capacity of steel tubes and its other properties. The incorporation of fiber has become the main approach for improving the mechanical properties of concrete. At present, fibers used in concrete mainly include steel fiber, glass fiber, synthetic fiber, basalt fiber, and carbon fiber [1], [2], [3], [4]. Basalt fiber is made by wiredrawing bushing plate through platinum rhodium after melting pure natural basalt ore, which has dark brown appearance and metallic luster, at High temperatures $\left(1450-1500^{\circ} \mathrm{C}\right)$. Basalt fiber possesses advantageous characteristics such as high tensile strength, high elasticity modulus, corrosion resistance, good chemical stability, and no discharge or pollution during production and use. As such, this material has gained increasing attention in engineering application [5], [6]. Existing studies have focused mainly on the basic mechanical properties of BFRC; however, basalt fiber is rarely used in concrete

\footnotetext{
*E-mail address: wxz0419314@163.com

ISSN: 1791-2377 @ 2016 Eastern Macedonia and Thrace Institute of Technology. All rights reserved.
}

structure engineering, let alone CFST structures. Therefore, the present study investigates the reinforcing effect of basalt fiber on the bearing capacity of long CFST columns and promotes the application of basalt fiber in CFST structures to elucidate the extent of the influence of basalt fiber on the ultimate bearing capacity of CFST under axial compression.

\section{State of the art}

Basalt fiber is an environmentally friendly material that can be divided into fiber cloth and chopped fiber. Basalt fiberreinforced concrete (BFRC) is formed by adding a small quantity of chopped basalt fiber to concrete. To examine the mechanical characteristics of BFRC, Dias performed strength tests on BFRC added with $1 \%$ mixing amount and compared the results with those for ordinary concrete under the same conditions; the compression resistance and splitting tension strength of BFRC decreased by $26.4 \%$ and $12 \%$, respectively, whereas its flexural-tensile strength increased by $45.8 \%$ [7]. Sim conducted strength tests on fiber concretes with different mixing amounts; the results indicated that compared with ordinary fiber concrete, BFRC displayed improved tensile strength (by 0.5-1 times), toughness (by 3-5 times), tensile failure mode, and tensile bearing capacity [8]. Kabay analyzed the anti-crack and wear-resisting properties of BFRC with different mixing amounts; the findings suggested that basalt fiber can improve the toughness strength, anti-crack performance, and corrosion resistance of concrete even under low mixing 
amounts [9]. To promote the application of basalt fiber in road and bridge engineering, Morova conducted a Marshall stability test on basalt fiber-reinforced bituminous concrete and evaluated the feasibility of applying basalt fiber in pavement under hot mix with bituminous concrete; the optimal proportion of the mixing amount of basalt fiber was $0.5 \%$ [10]. By performing a quasi-static flexural-tensile test, Asprone discovered that basalt fiber induced a toughening effect in mortar, and that compared with the plain mortar, the toughened mortar exhibited stronger toughness and higher sensitivity to the strain rate [11]. Najafi declared that basalt fiber can significantly enhance the impact toughness of concrete and that stronger toughness characteristics can be obtained when basalt fiber is mixed with carbon fiber (impact energy reaching up to $219 \mathrm{~kJ} / \mathrm{m} 2$ ) [12]. Li Weimin used a $\Phi 100 \mathrm{~mm}$ split Hopkinson pressure bar testing apparatus to examine the impact mechanical behavior of BFRC under different strain rates; the results indicated that the impact compression strength and energy absorbing ability of BFRC were obviously improved when compared with those of plain concrete and that BFRC displayed BFRC excellent impact mechanical properties [13].Few studies have explored the use of BFRC load-bearing members. In an experiment on composite steel-concrete columns and basalt additives, AlBaijat [14] added different percentages of basalt into concrete to investigate the compression failure on concrete, the buckling of steel section, and the de-bonding performance of steel and concrete. Results indicated that as the percentage of basalt content was increased, the structural behaviors and strength of the columns were significantly improved. Wang Hailiang [15] conducted an axial compression experimental analysis on short BFRC-filled steel tube columns and verified that basalt fiber induced a good toughening effect on short CFST columns. Under a given experimental level, the bearing capacity of short CFST columns was predominantly influenced by the steel ratio, followed by basalt fiber and concrete strength. References [7], [8] determined the optimal mixing amount of basalt fiber and its toughening effect on concrete. References [8], [9], [10] mainly studied the anti-crack, corrosion-resisting, and toughening functions of fiber concrete. References [11], [12] investigated the dynamic toughening effect of basalt fiber on concrete. Although these works have promoted the application of basalt fiber in concrete, they were limited to the changes in the mechanical properties of concrete itself. References [13], [14] provided reference for the application of basalt fiber in steel-concrete composite structures, but their findings were applicable only for fiber concrete in short columns. In practical engineering, long columns are mainly used in CFST structural engineering. Given that long columns differ from short columns during axial compression-caused failure in both failure mode and ultimate bearing capacity, the bearing capacity of long columns in BFRC-filled steel tubes must be examined to clarify the reinforcing function of long BFRC-filled steel tube columns under axial compression. Such an endeavor promotes the application of basalt fiber in steel-concrete composite structures. Thus, 15 long BFRC-filled steel tube columns and 9 long CFST columns were designed in this paper. An axial compression bearing capacity test was implemented on the long columns. Then, by conducting comparative tests, the reinforcing effect of basalt fiber on long CFST columns under axial compression was determined.

The remainder of this paper is organized as follows. Section 3 describes the research method and provides the mixing proportions of concrete, the parameters of the basalt fiber material, the mechanical indexes of the steel tube materials, and the experimental procedures. Section 4 discusses the experimental results and enumerates the differences in characteristics of the experimental columns. Section 5 summarizes the paper and presents the drawn conclusions.

\section{Methodology}

\subsection{Mixing proportion of core concrete}

This study adopted a comparative experiment. The cement used in the experiment was (P.O 42.5) ordinary Portland cement. The gravel was under grading distribution with diameter of 5-26.5 mm. Continuous two-graded distribution was used, and the crushing strength was 10.5. The grit fineness modulus was 28.5. The water was tap water. Super plasticizer and concrete were used as micro-expanding agents. The mixing proportion of concrete is shown in Table. 1

Table 1 Mixing Proportion of Core Concrete

\begin{tabular}{l|l|l|l|l|l|l|l}
\hline Concrete Strength & $\begin{array}{l}\text { Water-binder ratio } \\
(\%)\end{array}$ & $\begin{array}{l}\text { Cement } \\
\left(\mathbf{k g} \cdot \mathbf{m}^{-3}\right)\end{array}$ & $\begin{array}{l}\text { Water } \\
\left(\mathbf{k g} \cdot \mathbf{m}^{-3}\right)\end{array}$ & $\begin{array}{l}\text { Grit } \\
\left(\mathbf{k g} \cdot \mathbf{m}^{-3}\right)\end{array}$ & $\begin{array}{l}\text { Gravel } \\
\left(\mathbf{k g} \cdot \mathbf{m}^{-3}\right)\end{array}$ & $\begin{array}{l}\text { Water reducing agent } \\
\left(\mathbf{k g} \cdot \mathbf{m}^{-3}\right)\end{array}$ & $\begin{array}{l}\text { Expanding agent } \\
\left(\mathbf{k g} \cdot \mathbf{m}^{-3}\right)\end{array}$ \\
\hline $\mathrm{C} 50$ & 0.35 & 401 & 156 & 502 & 1201 & 4.5 & 44.5 \\
\hline
\end{tabular}

\subsection{Basalt fiber material parameters of the experimental model}

The basalt fiber material used in this experiment was chopped basalt fiber provided by Zhejiang GBF. Two Basalt Fibers of Different Lengths are shown in Fig.1, The concrete parameters are shown in Table 2.

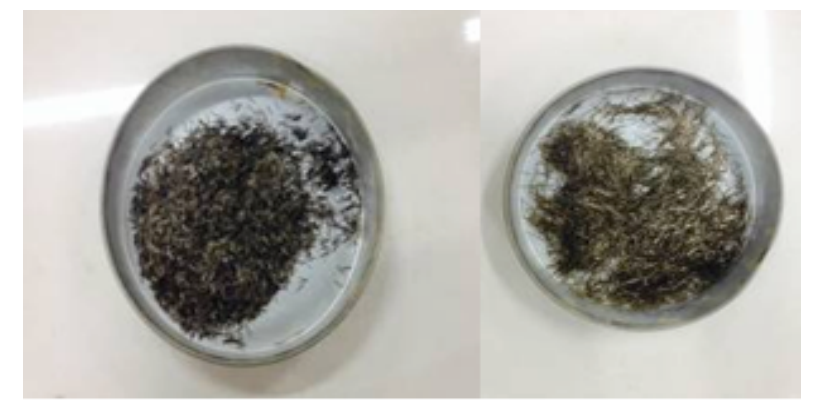

Fig. 1. Two Basalt Fibers of Different Lengths

Table 2. Basalt fiber parameters

\begin{tabular}{l|c|c|c|c}
\hline Fiberdiamete $(\boldsymbol{\mu m})$ & Fiber length $(\mathbf{m m})$ & Fiber density $\left.\mathbf{( k g} \cdot \mathbf{m}^{-3}\right)$ & Tensile strength(Mpa) & Elasticity modulus(MPa) \\
\hline 17 & 12 & 2650 & 3000 & 90 \\
17 & 24 & 2650 & 3000 & 90 \\
\hline
\end{tabular}




\subsection{Steel tube material parameters in the experiment}

The steel tubes used in this experiment were Q345B seamless steel tubes of three different wall thicknesses.
They were designed as long columns with an outer diameter of $108 \mathrm{~mm}$ and steel tube length of $0.980 \mathrm{~m}$. The concrete parameters are shown in Table 3.

Table 3. Steel tube parameters

\begin{tabular}{l|l|l|l|l|l}
\hline Steel tube type & Outer diameter $(\mathbf{m m})$ & Inner diameter $\mathbf{( m m})$ & Wall thickness $\mathbf{( m m})$ & Yield strength(MPa) & Elasticity modulus(MPa) \\
\hline 1 & 108 & 100 & 4 & 345 & $2.06 \mathrm{E}+05$ \\
2 & 108 & 98 & 5 & 345 & $2.06 \mathrm{E}+05$ \\
3 & 108 & 96 & 6 & 345 & $2.06 \mathrm{E}+05$ \\
\hline
\end{tabular}

\subsection{Model making}

In this experiment, a total of 24 long columns were made with three wall thicknesses of 4,5, and $6 \mathrm{~mm}$ and lengths of $980 \mathrm{~mm}$. Among the 24, 9 were long CFST columns (fiber mixing amount: $0 \%$ ), 9 were long BFRC-filled steel tube columns with fiber length of $12 \mathrm{~mm}$, and 6 were long BFRC-filled steel tube columns with fiber length of $24 \mathrm{~mm}$. For all cases, the mixing amount of basalt fiber in core concrete was $0.15 \%$.

\subsection{Experimental loading process}

This experiment was completed in a structural engineering laboratory in the School of Architecture and Construction, Hunan City University. The test site is shown in Fig. 2.

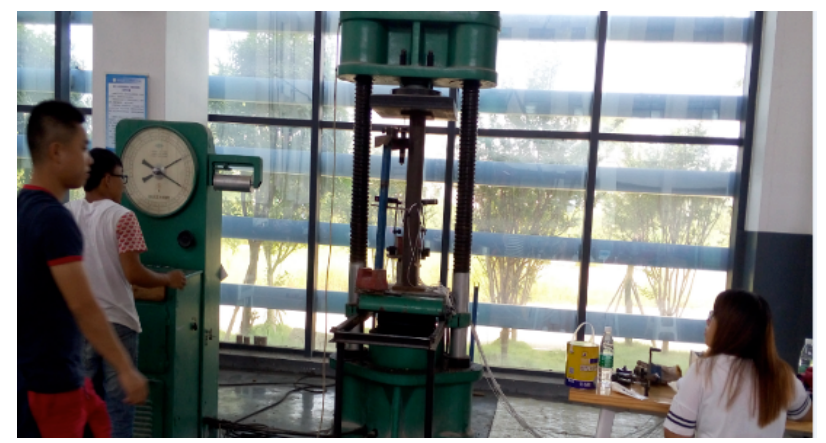

Fig. 2. Field Test Picture of Long Columns under Axial Compression

The experiment utilized one-way repeated loading and unloading, in which each specimen was first loaded with 20 $\mathrm{KN}$ for a load holding time of $3 \mathrm{~min}$ to observe the reliability of the loading system and work at measuring points. After pre-loading was completed, unloading was implemented, and loading was formally started. The formal loading adopted a gradation loading system, in which every gradation was loaded with $40 \mathrm{KN}$ for a holding time of 2 min for each gradation until failure. Resistance strain gauges were uniformly arranged in the middle of each specimen. Eight measuring points were observed. The loop and longitudinal directions of each measuring point were respectively installed with one strain gauge, as shown in Fig.3. Three displacement meters were installed to measure specimen deformation. Displacement meter 1 measured the vertical deformation of the specimen. Displacement meters 2 and 3 were placed on the side face of the column in 90degree angles to measure the lateral deformation in the middle of specimen. Measuring points positions are shown in Fig4. The displacement and strain values corresponding to each gradation of load were recorded.

\section{Results analysis and discussion}

\subsection{Experimental phenomena}

The specimen failure mode is shown in Fig.5. Not all of the specimens presented a local bulge during the loading process to the peak value. No obvious transverse displacement and deformation phenomena were observed on the CFST columns before the ultimate load was reached. All of the columns lost their load-bearing capacity during the transverse bending process, thereby suggesting that all failure modes were buckling failures. The long BFRC-filled steel tube columns and the long CFST columns presented no significant differences in the failure phenomenon.In addition, accompanied by vertical displacement, the middle of the steel tube experienced lateral bending, which was not obvious at the starting phase but eventually became apparent when the load increased to $80 \%-90 \%$ of the peak value. Compared with CFST columns, BFRC-filled steel tube columns experienced suddenly enlarged lateral displacement a little later.

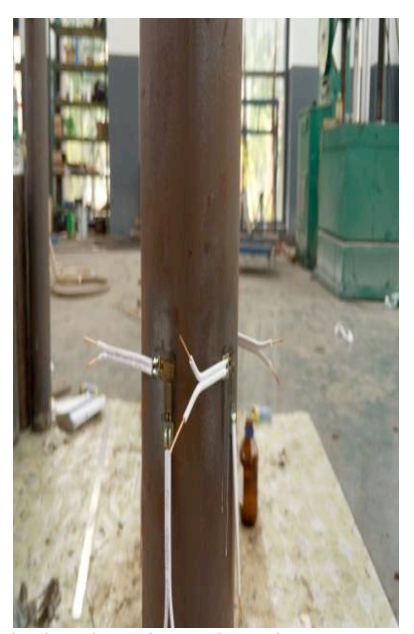

Fig. 3. Picture of Vertical and Horizontal Strain Gauges

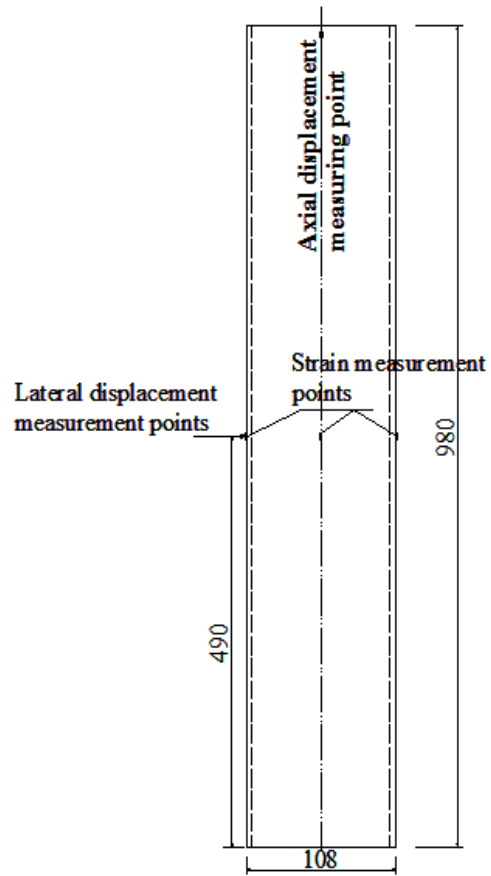

Fig. 4. Schematic Diagram of Column Dimension and Measuring Points 


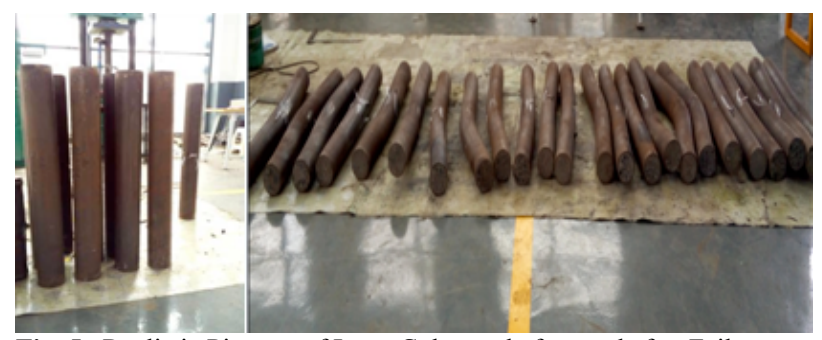

Fig. 5 . Realistic Pictures of Long Columns before and after Failure

\subsection{Experimental results}

Table 4 shows that under the same conditions, the ultimate Bearing capacity of long steel fiber-reinforced CFST columns mixed with $12 \mathrm{~mm}$ of basalt fiber was improved when compared with that of long CFST columns. The ultimate bearing capacities of BFRC-filled steel tubes with wall thicknesses of 4,5 , and $6 \mathrm{~mm}$ were improved by $9.9 \%$, $8.6 \%$, and $7.3 \%$, respectively. Under the same conditions, the ultimate bearing capacities of long steel fiber -reinforced concrete steel tube columns mixed with $24 \mathrm{~mm}$ basalt fiber were improved to a lower extent when compared with long CFST columns,. The ultimate bearing capacities of BFRCfilled steel tubes with wall thicknesses of 4,5 , and $6 \mathrm{~mm}$ were improved by $7.8 \%, 5.1 \%$, and $3.1 \%$, respectively. The contribution of $12 \mathrm{~mm}$ basalt fiber to the improvement of the ultimate bearing capacity of BFRC-filled steel tubes was superior to that of $24 \mathrm{~mm}$ basalt fiber, and the improvement rate of the ultimate bearing capacity gradually decreased as the steel tube wall thickness increased. In addition, although basalt fiber induced an enhancing effect on CFSTs with three wall thicknesses, its improvement rate of the ultimate bearing capacity was smaller than the improvement rate of the concrete compression strength, suggesting that this CFST experiment failed to fully maximize the enhancing effect of fiber on concrete. Further studies are needed to determine the optimal proportion among the enhancing effect of basalt fiber on CFST, steel tube wall thickness, fiber content, and concrete strength.

Table 4. Experimental Results of Long BFRC-Filled Steel Tube Columns under Axial Compression

\begin{tabular}{|c|c|c|c|c|c|}
\hline Column No. & $\begin{array}{c}\text { Outer diameter } \\
(\mathrm{mm})\end{array}$ & $\begin{array}{l}\text { Fiber mixing } \\
\text { amount }(\%)\end{array}$ & $\begin{array}{c}\text { Wall thickness } \\
(\mathrm{mm})\end{array}$ & $\begin{array}{l}\text { Fiber length } \\
(\mathrm{mm})\end{array}$ & $\begin{array}{c}\text { Ultimate bearing capacity } \\
(\mathrm{KN})\end{array}$ \\
\hline BF-0-4-1 & 108 & 0 & 4 & 1 & 960 \\
\hline BF-0-4-2 & 108 & 0 & 4 & / & 960 \\
\hline BF-0-4-3 & 108 & 0 & 4 & / & 920 \\
\hline BF-0-5-1 & 108 & 0 & 5 & l & 1080 \\
\hline BF- $0-5-2$ & 108 & 0 & 5 & l & 1080 \\
\hline BF- $0-5-3$ & 108 & 0 & 5 & l & 1080 \\
\hline BF-0-6-1 & 108 & 0 & 6 & / & 1280 \\
\hline BF-0-6-2 & 108 & 0 & 6 & i & 1280 \\
\hline BF-0-6-3 & 108 & 0 & 6 & / & 1280 \\
\hline BF-12-4-1 & 108 & 0.15 & 4 & 12 & 1040 \\
\hline BF-12-4-2 & 108 & 0.15 & 4 & 12 & 1040 \\
\hline BF-12-4-3 & 108 & 0.15 & 4 & 12 & 1040 \\
\hline BF-12-5-1 & 108 & 0.15 & 5 & 12 & 1160 \\
\hline BF-12-5-2 & 108 & 0.15 & 5 & 12 & 1160 \\
\hline BF-12-5-3 & 108 & 0.15 & 5 & 12 & 1200 \\
\hline BF-12-6-1 & 108 & 0.15 & 6 & 12 & 1400 \\
\hline BF-12-6-2 & 108 & 0.15 & 6 & 12 & 1360 \\
\hline BF-12-6-3 & 108 & 0.15 & 6 & 12 & 1360 \\
\hline BF-24-4-1 & 108 & 0.15 & 4 & 24 & 1040 \\
\hline BF-24-4-2 & 108 & 0.15 & 4 & 24 & 1000 \\
\hline BF-24-5-1 & 108 & 0.15 & 5 & 24 & 1120 \\
\hline BF-24-5-2 & 108 & 0.15 & 5 & 24 & 1160 \\
\hline BF-24-6-1 & 108 & 0.15 & 6 & 24 & 1320 \\
\hline BF-24-6-2 & 108 & 0.15 & 6 & 24 & 1320 \\
\hline
\end{tabular}

\subsection{Load-strain curves}

As shown in Fig.6, the load-loop strain curves had no yield in both long BFRC-filled steel tube columns and long CFST columns for wall thicknesses of 4 and $5 \mathrm{~mm}$. Before the load peak value was reached, the load-loop strain presented a linear-elastic relation. The columns with greater wall thicknesses displayed a more obvious elastic-plastic phase, and the loop strain of long BFRC-filled steel tube columns was higher than that of long CFST columns under failure. As shown by the load-axial strain curves in Fig.7, for long columns with wall thicknesses of 4 and $5 \mathrm{~mm}$, before the load peak value was reached, the load-vertical strain curves presented a linear-elastic relation. Long columns with wall thickness of $6 \mathrm{~mm}$ manifested no obvious elastic-plastic phase. In the starting phase, the vertical strain developed very rapidly, and the stain of BFRC-filled steel tube columns was smaller than that of CFST columns under the same conditions. At the peak value, the strain of BFRC-filled steel tube columns was greater than that of CFST columns, indicating that BFRC improved the ductility of CFST and enabled it to better adapt to deformability. Before the peak value was reached, the loop strain was small, and both the horizontal and vertical directions of the steel tubes did not have yield, indicating that the ultimate characteristics did not appear until the peak value was reached. As the load was increased, the deformation exceeded the allowable deformation limit of the concrete. The concrete was the first to suffer failure, and the peak value instantly appeared in the specimens. 

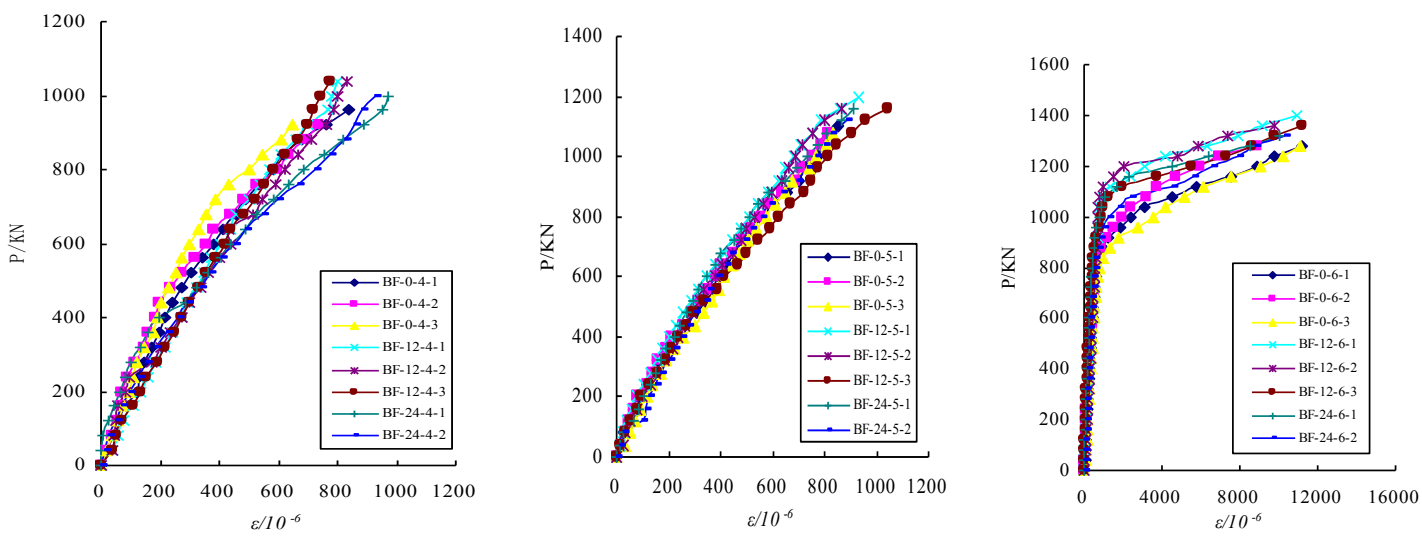

Fig. 6. Load-Loop Strain Curves
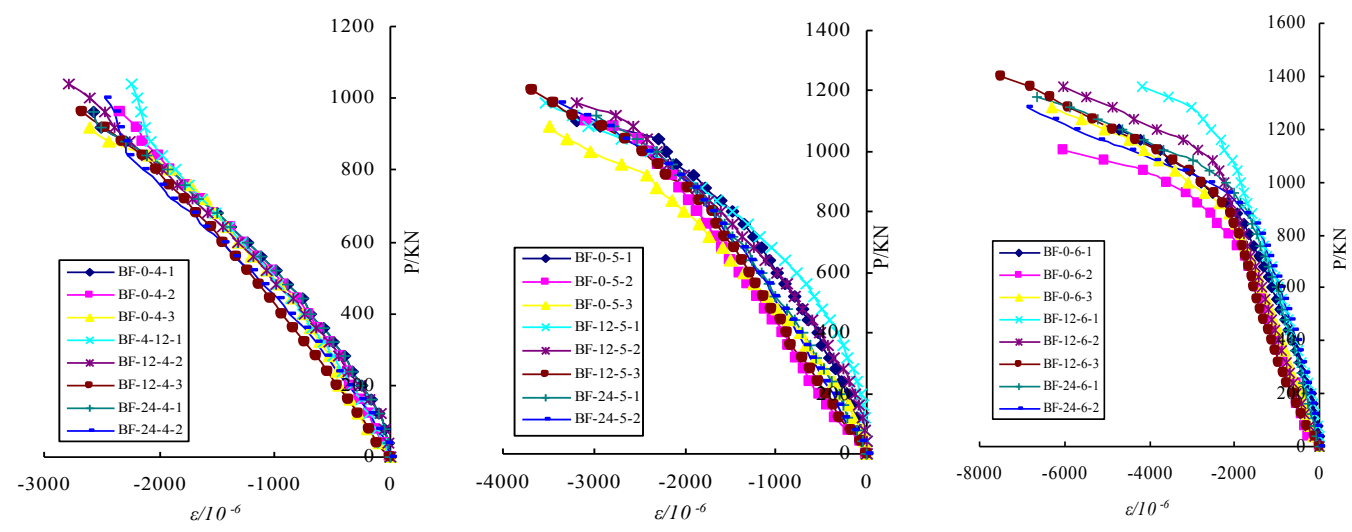

Fig. 7. Load-Axial Strain Curves

\subsection{Load-displacement curves}

As shown by the load-axial displacement curves in Fig.8, compared with CFST columns, BFRC-filled steel tube columns had small early displacements, presenting a linear relationship. When load reached $70 \%-80 \%$ of the ultimate load, the axial displacement became significantly increased. At the load peak value, the displacements of BFRC-filled steel tube columns were obviously greater than the axial displacements of CFST columns, suggesting that BFRC-
Filled steel tube columns had better ductility. During the loading process of CFST, the steel tubes entered an elasticplastic phase from an elastic phase. Three specimens manifested obviously enlarged axial displacements, and their curves were consistent. This finding indicates that although basalt fiber induced a reinforcing effect on CFST and improved ductility, its influence on the failure mode of CFST was not significant.
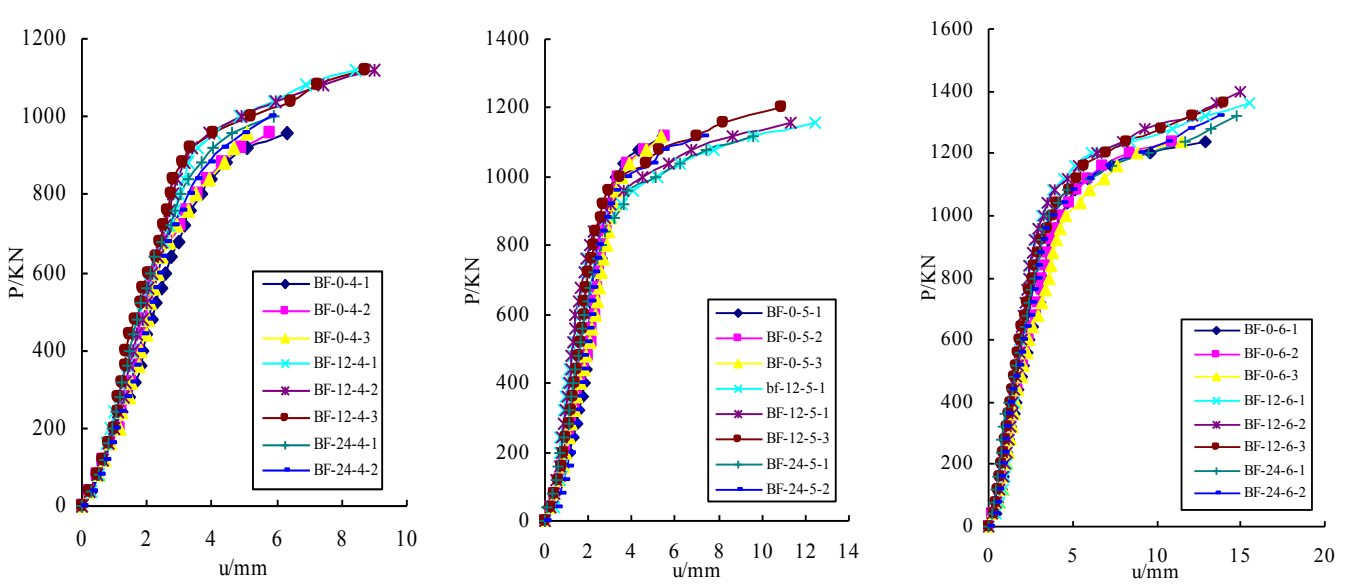

Fig. 8. Load-Axial Displacement Curves

\section{Conclusion}

Bearing capacity experiments were conducted on long BFRC-filled steel tube columns and long CFST columns under the same experimental conditions to analyze the influence of basalt fiber on the mechanical properties of long
CFST columns under axial compression and to clarify the reinforcing effect of basalt fiber on long CFST columns. The main conclusions are as follows:

(1) Under the same conditions, compared with long CFST columns, long BFRC-filled steel tube columns had improved ultimate bearing capacities; the maximum 
improved value was $120 \mathrm{KN}$ with a maximum improvement rate of $9.9 \%$. The improvement rate decreased as the wall thickness (steel rate) increased.

(2) When the ultimate bearing capacity was reached, all experimental columns did not present obvious yield or outward bulge of the steel tube. Furthermore, under the same conditions, the axial displacement and strain of long BFRCfilled steel tube columns were greater than those of long CFST columns, thereby verifying that the ductility of long BFRC-filled steel tube columns was superior to that of long CFST columns and that ductility increased as the wall thickness (steel rate) increased.

(3) Basalt fiber can be utilized as an enhancing material for long CFST columns. Basalt fibers of different lengths induced varying toughening effects on CFST. The toughening effect of $12 \mathrm{~mm}$ basalt fiber on long BFRC-filled steel tube columns under axial compression was superior to that of $24 \mathrm{~mm}$ basalt fiber.

The reinforcing effect of basalt fiber on long CFST columns under axial compression was analyzed by conducting a comparative experiment. The obtained conclusions are beneficial for future studies on improving the reinforcing effect and ductility of basalt fiber on long CFST columns. However, given that the experimental data in this study were limited and the slenderness ratio was single, the drawn conclusions suffer from certain limitations. Therefore, future works should concentrate on incorporating additional gradations (different slenderness ratios, fiber mixing amounts, mixing proportions, etc.) of long BFRCfilled steel tube columns to obtain more accurate data on the enhancing effect of basalt fiber on long CFST columns under axial compression.

\section{References}

1. Lu Yiyan, Chen Juan, Li Shan, "Experimental Study on Axial Compression of Short Steel Fiber Reinforced High-Strength Concrete-filled Steel Tube Columns". Journal of Architectural Structure, 32(10), 2011, pp.166-172.

2. Banthia, N., Sappakittipakorn, M., "Toughness enhancement in steel fiber reinforced concrete through fiber hybridization". Cem Concr Res, 37(9), 2007, pp.1366-1372.

3. Felekoglu, B., Tosun, K., Baradan, B., "Effects of fibre type and matrix structure on the mechanical performance of self-compacting micro-concrete composites". Cem Concr Res, 39(11), 2009, pp. 1023-1032.

4. Hannant, D. J., "Fibre reinforced concrete". In: Newman J, Choo BS, editors. Advanced concrete technology-processes, Oxford: An Imprint of Elsevier, 2003, pp.146-163.

5. Sayyed Mahdi Abtahi, Mohammad Sheikhzadeh, Sayyed Mahdi Hejazi, "Fiber-reinforced asphalt-concrete-A review". Construction and Building Materials, 24(1), 2010, pp.871-877.

6. Serge, Li Zhongying, "Application Prospect of Basalt Fiber Materials". Fiberous Composite Materials, 3, 2003, pp.7-20.

7. Dylmar Penteado Dias, Clelio Thaumaturgo, "Fracture toughness of geopolymeric concretes reinforced with basalt fibers". Cement \&Concrete Composites, 27(1), 2005, pp.49-54.

8. JONG sung Sim, Cheolwoo Park,Do Young Moon,"Characteristics of basalt fiber as a strengthening material for concrete structures". Composites Part B, 36(6), 2005, pp.504-512.
9. MOROVA, N., "Investigation of Usability of Basalt Fibers in Hot Mix Asphalt Concrete". Construction and Building Materials, 47(10), 2013, pp.175-180.

10. ASPRONE, D., CADONI, E., IUCOLANO, F., "Analysis of the Strain-rate Behavior of a Basalt Fiber Reinforced Natural Hydraulic Mortar". Cement \& Concrete Composites, 53 (10), 2014, pp.52-58.

11. KABAYN, Abrasion, "Resistance and Fracture Energy of Concretes with Basalt Fiber". Construction and Building Materials, 50(1), 2014, pp.95-101.

12. NAJAFI, M., KHALILI, S. M. R., ESLAMI-FARSANI, R., "Hybridization Effect of Basalt and Carbon Fibers on Impact and Flexural Properties of Phenolic Composites". Iranian Polymer Journal, 23(10), 2014, pp.767-773.

13. Li Weimin, Xu Jinyu, "Impact Mechanical Behaviors of Basalt Fiber Reinforced Concrete and its Constitutive Model". Engineering Mechanics, 26(1), 2009, PP. 86-91.

14. Hamadallah Al-Baijat, Andrea Benedetti, "Comparison between Composite Column Using Limestone and Basalt Concrete". Open Journal of Civil Engineering, 3(1), 2013, pp.1-6.

15. Wang Hailiang, Duan Xiaoxia, Yang Xinlei, "Experimental Study on Mechanical Properties of Short BFRC-Filled Steel Tube Columns". Industrial Architecture, 45(6), 2015, pp.150-153. 